\title{
Medicina Narrativa, José Saramago e a Pandemia
}

\author{
Narrative Medicine, José Saramago and the Pandemic \\ Medicina narrativa, José Saramago y la pandemia
}

\author{
Luciana Andrade ${ }^{1}$ \\ Ana Paula de Jesus Ferreira Fernandes ${ }^{2}$ \\ Thais Batalha Campello ${ }^{3}$
}

\begin{abstract}
Resumo: Este artigo apresenta as estratégias de introdução da obra de José Saramago no ensino da medicina numa perspectiva da Medicina Narrativa atrelada ao contexto pandêmico da Covid-19. Em "As Intermitências da Morte", um cenário fictício traz a Morte fazendo greve, interrompendo todos os óbitos. Em "Ensaio sobre a Cegueira", uma epidemia atinge uma cidade deixando quase todos os habitantes cegos. Em ambos os casos, um grande desequilíbrio recai sobre a população que precisa aprender a viver com as novas situações de caos social e político. A partir dessas histórias, discussões literárias nas disciplinas de Geriatria, Bioética, Oftalmologia, Epidemiologia e outras podem tornar o ensino da medicina mais dinâmico e humanizado, fomentando a reflexão sobre as particularidades socioeconômicas, políticas e culturais vivenciadas pelas pessoas que buscam atendimento de saúde, sobretudo no contexto brasileiro do Sistema Único de Saúde.
\end{abstract}

Palavras-chave: Literatura; Humanização da Assistência; Medicina Narrativa, Pandemia.

Abstract: This article presents the strategies for introducing José Saramago's work in the teaching of medicine from a perspective of Narrative Medicine linked to the pandemic context of Covid-19. In "Death with Interruptions", a fictional scenario brings Death on strike, interrupting all deaths. In "Blindness", an epidemic hits a city leaving almost all the inhabitants blind. In both cases, a great imbalance falls on the population that needs to learn to live with the new situations of social and political chaos. Using these books, literary discussions in the disciplines of Geriatrics, Bioethics, Ophthalmology, Epidemiology, and others can make the teaching of medicine more dynamic and humanized, fostering reflection on the socioeconomic, political, and cultural particularities experienced by people seeking health care, especially in the context of the Brazilian National Health System.

Keywords: Literature; Humanization of Assistance; Narrative Medicine, Pandemic.

Resumen: Este artículo presenta las estrategias para introducir el trabajo de José Saramago en la enseñanza de la medicina desde una perspectiva de Medicina Narrativa vinculada al contexto pandémico del Covid-19. En "Las Intermitencias de la Muerte", un escenario ficticio pone a la Muerte en huelga, interrumpiendo todas las muertes. En "Ensayo sobre la Ceguera", una epidemia golpea una ciudad dejando ciegos a casi todos los habitantes. En amboscasos, un gran desequilibrio recae sobre la población que necesita aprender a convivir con las nuevas situaciones de caos social y político. Las discusiones literarias en las disciplinas de Geriatría, Bioética, Oftalmología, Epidemiología y otras pueden hacer que la enseñanza de la medicina sea más dinámica y humanizada, fomentando la reflexión sobre las particularidades socioeconómicas, políticas y culturales que viven las personas que buscan atención de salud, especialmente en el contexto del Sistema Nacional de Salud brasileño.

Palabras clave: Literatura; Humanización de la asistencia; Medicina Narrativa, Pandemia.

\footnotetext{
${ }^{1}$ Bióloga pela UERJ, mestre e doutora em Biofísica pela UFRJ, professora e coordenadora da comissão de ética em pesquisa na Estácio de Sá.

${ }^{2}$ Estudante de Medicina, bolsista do projeto Ciclo Saúde gerido pelo Centro de Promoção da Saúde e atua em Projeto de Iniciação Científica e de Extensão na Universidade Estácio de Sá. Enfermeira pelo Centro Universitário São Camilo, com atuação em Estratégia Saúde da Família.

${ }^{3}$ Estudante de medicina da Universidade Estácio de Sá. Atualmente cursando o Internato Médico.
} 


\section{Introdução}

Experiências de introdução de disciplinas relacionadas às humanidades e às artes têm sido descritas nas escolas médicas no Brasil e no mundo nos últimos 25 anos. Percebe-se, porém, que existem dificuldades para a integração dessas matérias no currículo médico de forma sistêmica, não isoladas e não periféricas como ainda é comum. Para isso, são necessárias estratégias que demonstrem para estudantes e professores a relevância da inclusão das humanidades na formação do profissional da área da saúde.

Embora a medicina seja considerada uma arte, praticada de acordo com os referenciais científicos, a educação médica tem se voltado exaustivamente para os aspectos técnicos da prática clínica, procurando preparar o estudante para condutas eficazes na detecção, remissão e cura das doenças. Este movimento acaba por desconsiderar os aspectos humanos do cuidado, demonstrando uma carência que se revela nos desencontros que vem se perpetuando nas relações médico-paciente ${ }^{4}$.

A maioria dos problemas de saúde não depende de soluções exclusivamente técnicas. Sofrimento, depressão, alienação, doença crônica, incapacidade e morte são problemas de abordagem predominantemente não técnicas - problemas que dizem respeito à condição humana e que necessitam de acuidade de percepção, habilidade de comunicação - um tipo de expertise tradicionalmente associada às artes 5 .

Nesse contexto é que se tem observado uma tentativa de introdução das humanidades no ensino médico ${ }^{6}$. Atividades de educação envolvendo a literatura e o uso de filmes, por exemplo, têm sido descritas como uma possibilidade de estímulo à formação humanística do médico ${ }^{7,8,9}$, além de também incorporarem metodologias mais dinâmicas de ensino ${ }^{10,11}$.

\footnotetext{
${ }^{4}$ Miguel Kottow. ?Bioética narrativa o narrativa Bioética? Revista Latinoamericana de Bioética, 16, 2 (2016): 58.

${ }^{5}$ Larry Churchill. Why literature and medicine? Literature and Medicine, 1(1) (1982): 35.

${ }^{6}$ José Ricardo de Carvalho Ayres, et al. Humanidades como disciplina da graduação em medicina. Rev Bras Educ Méd, 37, 3 (2013): 455.

${ }^{7}$ Fátima Geovanini et al. Todo aluno tem uma história para contar: narrativas dos estudantes na disciplina de humanidades médicas. Revista Eletrônica Estácio Saúde, 5, 2 (2016): 169.

${ }^{8}$ Ana Luisa Rocha Mallet, et al. Cardiology and films: an important teaching tool. International Journal of Cardiovascular Sciences, 31, 4 (2018): 451

${ }^{9}$ Marlon Ribeiro da Silva, et al. Literatura e Humanização: uma experiência didática de educação humanística em saúde. Rev Bras Educ Méd, 40, 1 (2016): 93.

${ }^{10}$ Poliana Cruz, et al. Percepção da efetividade dos métodos de ensino utilizados em um Curso de Medicina do Nordeste do Brasil. Rev Bras Educ Méd, 43, 2 (2019): 40.

${ }^{11}$ Artur Dias Lima, et al. Avaliação, ensinagem e metodologias ativas: uma experiência vivenciada no componente curricular Mecanismos de Agressão e de Defesa, no Curso de Medicina da Universidade do Estado da Bahia, Brasil. Rev Bras Educ Méd, 43, 2 (2019): 216.
} 
José Saramago, vencedor do Prêmio Nobel da Literatura em1998 com o livro "Ensaio sobre a Cegueira" 12 , foi o ponto de partida de um projeto de iniciação científica no qual duas estudantes de medicina criaram materiais para utilização em disciplinas médicas, e produziram contos e vídeos infantis no contexto da pandemia de Covid-19. Tanto o livro que lhe deu o prêmio quanto outra obra de sua autoria, "As intermitências da Morte"13, foram utilizados nesse projeto.

Em "Ensaio sobre a Cegueira", uma epidemia atinge uma cidade fictícia deixando quase todos os habitantes cegos. Em "As intermitências da Morte", outro cenário fictício mostra uma Morte que faz greve, de tal sorte que ninguém mais morre. Essa situação acaba gerando um caos social e político. Em ambos os casos, um grande desequilíbrio recai sobre a população que precisa aprender a viver com as novas situações.

Nascido em terras lusitanas, o português de visão vasta do mundo era um míope ousado na forma de pontuar (ou não pontuar) os textos. Saramago passou a usar como estilo o "fluxo verbal sem pressa de chegar, tal qual os contadores de histórias que nunca contam uma história duas vezes da mesma maneira"14. O autor desperta questionamentos sobre a prática médica e sobre o processo de adoecimento: Será que o paciente é visto em sua totalidade ou selecionamos a turbidez de acordo com nosso propósito de olhar para a doença? Será que já cegamos ou estamos ensaiando uma cegueira para olhar o outro? A dignidade do ser humano é prioridade no cuidado ou esmaece frente a verdades individuais?

Sabe-se que a medicina e a literatura partilham de um território comum: ambas falam da dor, do sofrimento, das alegrias inusitadas das quais talvez jamais desfrutássemos caso alguém não se dispusesse a contar histórias ou escrevê-las. Saramago foi escolhido por sua perspicácia ao abordar o ser humano diante de suas mazelas. Ora como vítima, ora como algoz. Criador e criatura, mas sempre protagonista da sua história.

Assim, discussões em disciplinas tanto do ciclo básico, correspondente à fase inicial do curso de medicina, como Epidemiologia e Propedêutica, quanto do ciclo clínico como Cardiologia, Bioética, Oftalmologia e outras podem ser levantadas a partir desse material, tornando as aulas mais dinâmicas e fomentando a reflexão sobre as particularidades socioeconômicas, políticas e culturais vivenciadas pelas pessoas que buscam atendimento de saúde, sobretudo no contexto brasileiro do Sistema Único de Saúde (SUS).

\footnotetext{
12 José Saramago. Ensaio sobre a Cegueira (76 ${ }^{\mathrm{a}}$ reimpressão, São Paulo, Companhia das Letras, 2017).

${ }^{13}$ José Saramago. As Intermitências da Morte (17ª reimpressão, São Paulo, Companhia das Letras, 2016).

${ }^{14}$ Miguel G. Mendes. Documentário José e Pilar - tudo pode ser contado de outra maneira. Direção: Miguel Gonçalves Mendes, Edição: Cláudia Rita Oliveira. 2010. https://www.youtube.com/watch?v=d-V7j-WKHVs
} 


\section{Métodos}

Durante um projeto de iniciação científica desenvolvido de agosto de 2019 a julho de 2020, duas alunas leram as obras "Ensaio sobre a Cegueira" e "As Intermitências da Morte" de José Saramago, de forma a buscar, em ambas, trechos que pudessem ser utilizados para reflexão em diferentes disciplinas de uma escola de medicina. O objetivo principal do projeto era entregar à coordenação do curso sugestões da utilização de literatura em sala de aula, principalmente nas disciplinas consideradas mais técnicas. O objetivo secundário era a escrita de contos. Com a chegada da pandemia e um convite para a produção de material artístico para o Congresso Brasileiro de Educação Médica de 2020, as alunas se sentiram estimuladas a escrever contos e ainda, elaborar vídeos, trazendo as obras de Saramago para o cenário atual. Alguns contos e vídeos foram principalmente destinados ao público infantil.

\section{Resultados e Discussão}

Em uma análise conjunta das obras, as alunas selecionaram 62 excertos de ambos os livros com comentários de forma a auxiliar suas inserções em aulas de diferentes disciplinas do curso de graduação em medicina como Epidemiologia ( $2^{\circ}$ e $4^{\circ}$ períodos), Propedêutica Médica ( $4^{\circ}$ período), Cardiologia ( $6^{\circ}$ período), Bioética ( $7^{\circ}$ período), Oftalmologia ( $7^{\circ}$ período), Cuidados Paliativos ( $8^{\circ}$ período) e Saúde da Família e Comunidade (do $1^{\circ}$ ao $8^{\circ}$ períodos). Além disso, cada aluna ficou responsável pela produção de uma série de contos relacionados a uma das obras de Saramago. Com base em "As Intermitências da morte", uma delas produziu 10 contos, sendo 3 de natureza infantil. Já a outra produziu 3 contos inspirados em "Ensaio sobre a cegueira", e a partir de 2 contos infantis sobre "As Intermitências da morte", produzidos pela outra aluna, criou inúmeras ilustrações transformadas em dois vídeos como desenhos animados para crianças.

Os contos trouxeram as histórias de Saramago adaptadas à realidade da situação de quarentena devido à pandemia de Covid-19. Em dezembro de 2019 surgiu em Wuhan, na China, um surto de um novo vírus causador de uma síndrome respiratória aguda grave, um inimigo invisível com alto poder de transmissibilidade que rapidamente fechou fronteiras, interrompeu fluxos de pessoas e mercadorias, suspendeu eventos e lotou hospitais, alavancando o número de casos e consequente número de óbitos pelo vírus. 
Desde então foi necessária a implementação de diversas medidas de isolamento social, na tentativa de frear o contágio da população mundial ${ }^{15}$. Tais dados, por si só, já deflagram uma importante implicação político-social e de saúde mental, uma vez que o luto no momento pandêmico também ocorre sem a possibilidade de rituais de despedida, prejudicando uma vivência adequada do processo de morte. Essa situação, que lembra em muito as situações caóticas descritas por Saramago, trouxe inspirações às alunas para a criação de seus contos.

Nesse contexto, por exemplo, em um dos contos, uma mãe conta para sua filha parte da história de "As intermitências da Morte", de forma que a criança possa entender que morrer faz parte do ciclo da vida, ainda que no momento da pandemia, o número de mortes seja assustador, destacando que, mesmo diante da impossibilidade de cura, o conforto e o cuidado no processo de morte devem prevalecer.

A seguir, estão elencados alguns trechos selecionados de ambos os livros e as disciplinas de medicina com as quais podem estar relacionados: “... o médico rural que os visitava uma vez por semana dizia que já nada podia fazer por eles
nem contra eles, nem sequer injectar-lhes, a um e a outro, uma boa droga letal, daquelas que
não há muito tempo teriam sido a solução radical para qualquer problema.” (As intermitên-
cias da Morte, p. 38 e 39) - Bioética.
“... a partir de agora não precisarão de ficar nem um minuto, é só aquele tempo de morrer, e
esse, se sempre foi de todos o mais breve, um suspiro, e já está, pode-se imaginar bem o que
passou a ser neste caso, uma vela que de repente se apaga sem ser preciso soprar-lhe. Nunca
a mais suave das eutanásias poderá vir a ser tão fácil e tão doce.” (As intermitências da Morte,
p. 68) - Bioética.

"Embora, como já havia ficado dito antes, uma grande parte dos doentes sem cura e cuja enfermidade havia chegado ao seu extremo e derradeiro grau, se era lícito dizer tal de um estado nosológico que se havia anunciado como eterno, tivessem sido recambiados para as suas casas e famílias, Em que melhores mãos poderiam estar os pobres diabos..." (As intermitências da Morte, p. 115) - Cuidados Paliativos.

“... ninguém diria que é o primeiro violoncelista de uma orquestra sinfônica da cidade, que a sua vida discorre por entre as linhas mágicas do pentagrama, quem sabe à procura também do coração profundo da música, pausa, som, sístole, diástole." (As intermitências da Morte, p. 151) - Cardiologia.

“... basta dizer que os insectos não morrem por causas tão comuns na espécie humana como são, por exemplo, a pneumonia, a tuberculose, o cancro, a síndrome da imunodeficiência adquirida, vulgarmente conhecida como sida, os acidentes de viação ou as afecções cardiovasculares.” (As intermitências da Morte, p. 174) - Clínica Médica.

“... os olhos do homem parecem sãos, a íris apresenta-se nítida, luminosa, a esclerótica branca, compacta como porcelana.” (Ensaio sobre a Cegueira, p. 12) - Oftalmologia.

\footnotetext{
${ }^{15}$ World Health Organization. WHO | WHO Director-General's opening remarks at the media briefing on COVID-19 11 March 2020, https://www.who.int/director-general/speeches/detail/who-director-general-s-opening-remarks-at-themedia-briefing-on-covid-19---11-march-2020
} 


\begin{abstract}
"Vejo tudo branco, senhor doutor. Não falou do roubo do automóvel. O médico perguntoulhe, Nunca lhe tinha acontecido antes, quero dizer, o mesmo de agora, ou parecido, Nunca, senhor doutor, eu nem sequer uso óculos, E diz-me que foi de repente, Sim, senhor doutor, Como uma luz que se apaga, Mais como uma luz que se acende, Nestes últimos dias tinha sentido alguma diferença na vista, Não, senhor doutor." (Ensaio sobre a Cegueira, p.22) Propedêutica, Saúde da Família e comunidade.
\end{abstract}

\begin{abstract}
"Há, ou houve, algum caso de cegueira na sua família, Nos parentes que conheci ou de quem ouvi falar, nenhum, Sofre de diabetes, Não, senhor doutor, De sífilis, Não senhor doutor, De hipertensão arterial ou intracraniana, Da intracraniana não sei, do mais sei que não sofro, lá na empresa fazem-nos inspeções, Deu alguma pancada violenta na cabeça, hoje ou ontem, Não senhor doutor, Quantos anos tem, Trinta e oito, Bom, vamos lá então observar esses olhos.” (Ensaio sobre a Cegueira, p.22) - Saúde da Família e Comunidade.
\end{abstract}

"O cego abriu-os muito, como para facilitar o exame, mas o médico tomou-o por um braço e foi instalá-lo por trás de um aparelho que alguém com imaginação poderia ver como um novo modelo de confessionário, em que os olhos tivessem substituído as palavras, como o confessor a olhar diretamente para dentro da alma do pecador, Apoie aqui o queixo, recomendou, mantenha os olhos abertos, não mexa" (Ensaio sobre a Cegueira, p.23) - Epidemiologia.

"O médico subiu. E baixou o sistema binocular do seu lado, fez girar parafusos de passo finíssimo, e principiou o exame. Não encontrou nada na córnea, nada na esclerótica, nada na íris, nada na retina, nada no cristalino, nada na mácula lútea, nada no nervo óptico, nada em parte alguma. Afastou-se do aparelho, esfregou os olhos, depois recomeçou o exame desde o princípio sem falar, e quando outra vez terminou tinha na cara uma expressão perplexa." (Ensaio sobre a Cegueira, p.23) - Propedêutica.

Figura 1. Alguns dos desenhos produzidos pelas alunas de iniciação científica a partir dos contos baseados nas obras de José Saramago: "Ensaio sobre a Cegueira" e "As Intermitências da Morte"

\title{
Desdobramentos: Os Fatos e os Contos - Narrativas sobre a Cegueira e a Morte
}

Os excertos ainda não foram inseridos nas disciplinas como sugerido. No entanto, a leitura de Saramago despertou nas alunas de iniciação científica alguns questionamentos sobre a prática médica, pois hoje a assistência convive intensamente com máquinas e a frieza humana se instala no processo de adoecimento. A pessoa doente perde suas vestes nos hospitais, deixa de ser vista na sociedade, perde seus adereços, seu nome, sua identidade, vira doença e número como os personagens de "Ensaio sobre a Cegueira" e dos contos elaborados durante o projeto com inspiração na obra do autor.

Os odores, os sons, o urrar não verbal e o calar tornam o adoecer um aprendizado particular que todo médico deverá vivenciar em maior ou menor grau a depender de sua especialidade ou linha de atuação, mas (futuros) médicos devem desejar sempre enxergar a pessoa que necessita de seus cuidados. Nem sempre o papel será o de curar, mas de ajudar a caminhar, de cuidar e possibilitar meios de compreensão de determinados processos, assim como fazia a mulher do médico com os demais personagens. 
Dessa forma, os contos podem ser instrumentos para reflexão sobre o adoecimento e melhorar a capacidade comunicativa na relação médico-paciente. Segundo Finger Schneider ${ }^{16}$, contos são usados com função terapêutica há séculos. De acordo com a autora, a medicina hindu se utiliza de contos para estimular meditação e o exercício de personificação em pessoas com doenças de acometimentos mental.

Caldin ${ }^{17}$ comenta que a clínica psicanalítica também faz uso de contos infantis nas diferentes faixas etárias tanto para diagnóstico como para tratamento, visto tratar-se de uma oportunidade de introspecção fornecida pela literatura que atrai leitores e ouvintes, estimulando o pensamento sobre sentimentos, esperanças e sofrimentos. Além disso, a lembrança das histórias com as quais se tem contato pode fornecer conforto e estimular um repertório de soluções de conflitos que se adaptem à realidade na qual o contador ou o ouvinte estão inseridos.

Ainda segundo Caldin ${ }^{14}$ a universalização dos problemas fornecida pelos contos pode ser um meio de perceber que não estamos sozinhos em nossas dores. Dessa forma, o uso da literatura já consagrada e a elaboração de contos nela inspirados são formas de instigar o aluno de graduação em medicina a ver as sutilezas das necessidades dos indivíduos, ainda que não as vivencie completamente durante a prestação de cuidados; a leitura pode estimular previamente o pensamento crítico sobre quais seriam os motivos da crescente falta de empatia, buscando reparar em sua prática clínica os entraves para conquistar desfechos benéficos e um cuidado integral.

Surgiram outras ideias, como a criação de contos infantis e de diversos finais para uma mesma história. Além disso, durante a primeira fase do trabalho, um ganho significativo foi o contato com a forma de escrita que Saramago adota em suas obras, uma maneira rebuscada e com características próprias como a utilização de vírgulas na separação de falas em vez de travessões, assim como o uso raro de parágrafos. Desse modo, tendo em vista que a leitura dessa forma peculiar de escrita já havia sido enriquecedora, foi determinado pelas alunas que alguns contos seriam redigidos buscando ao máximo assemelhar-se a escrita de Saramago, objetivando maiores aventuras.

No livro "As Intermitências da Morte", o autor aborda temas como o processo de envelhecimento, a morte, a distanásia e os prejuízos que a ausência da morte pode acarretar, incluindo o sofrimento, demonstrando a necessidade do falecer, que, muitas vezes, é vista de forma negativa em nossa

\footnotetext{
${ }^{16}$ Raquel E.S. Finger Schneider \& Sandra D. Torossian. Contos de fadas: de sua origem à clínica contemporânea. Psicol. rev. 15, 2 (2009): 132.

${ }^{17}$ Clarice F. Caldin. A aplicabilidade terapêutica de textos literários para crianças: Encontros Bibbi. Revista Eletrônica de Biblioteconomia e Ciência da Informação, 18 (2004): 72.
} 
sociedade. Portanto, fica evidente que, para além da linguagem rebuscada, há conteúdos valiosos a serem apresentados às crianças.

Assim, foram desenvolvidos dois eixos: um deles formado por quatro a cinco contos, os quais seriam dirigidos ao público infantil, e outro com o mesmo número aproximado, unindo a linguagem e escrita autênticas do autor - incluindo os termos médicos e a utilização da dinâmica de criação de múltiplos finais para uma mesma história.

No tocante aos contos infantis, estes foram construídos com foco na primeira metade do livro, a qual aborda a suspensão das mortes no país e suas consequências. Buscou-se contextualizar os textos com acontecimentos e personagens do livro como, por exemplo, a rainha-mãe e os problemas advindos da greve da Morte. Nesses contos, o objetivo principal era apresentar os problemas que a suspensão dos falecimentos poderia acarretar, os quais não são pensados geralmente por crianças, e mostrar como a morte é necessária e, muitas vezes, benéfica. Também a distanásia ${ }^{18}$ foi abordada nos contos, com o objetivo de promover uma reflexão a respeito de a que ponto impedir a todo custo a morte propriamente dita é de fato benéfica ao doente. Com isso, além de estimular a leitura para essa faixa etária, foram desenvolvidos temas extremamente sérios e importantes para a vida das crianças de forma mais leve, utilizando uma linguagem acessível e tendo o universo infantil como protagonista. Para além de servirem só ao público infantil, essa literatura também é importante ferramenta para utilização com os alunos nas escolas médicas ${ }^{19}$.

\section{Considerações Finais: Literatura como Semente para a Humanização}

O reconhecimento dos limites terapêuticos e o prezar pelo cuidado do corpo que está morrendo são imprescindíveis ao fazer médico, mas, para isso, é necessário o emprego de estratégias no ensino médico que valorizem não somente a aquisição de conteúdos técnicos e científicos, mas também o aprimoramento de uma escuta atenta das mais diversas expressões de individualidade dentro do processo de morte e morrer em diferentes idades.

Consciente de que a relação paciente-médico não se esgota no diagnóstico de uma doença, o estudante de medicina pode reconhecer como fundamentais o estabelecimento contínuo de vínculo, a empatia, a escuta e leitura atenta ${ }^{20}$, o olhar para o não visto, em que cada palavra e os silêncios podem também ser terapêuticos.

\footnotetext{
${ }^{18}$ Clarissa Botega, Luiz Fernandes de Campos. Considerações sobre a Eutanásia, distanásia e ortotanásia e a bioética. Rev. Jurídica Universidade de Cuiabá (2011): 39.

${ }^{19}$ Ana L.R. Mallet et al. 2020. A diferent heart in children's literature: the juvenile literature in medical education. International Journal of Cardiovascular Sciences, 33, 2 (2020):185.

${ }^{20}$ Rita Charon. Narrative medicine: a model for empathy, reflection, profession, and trust. JAMA 286 (2001):1897.
} 
Dessa forma, faz-se necessário integrar as Humanidades e as Artes ao currículo médico de forma sistêmica a fim de contribuir para o desenvolvimento de competências e habilidades que propiciem o olhar para as sutilezas da assistência diante das necessidades dos indivíduos, família e comunidade em um processo contínuo de prestação de cuidados em saúde e de reflexão sobre a miopia crescente que traz dureza e falta de empatia.

\section{Referências}

Ayres, José Ricardo de Carvalho, Izabel Cristina Rios, Lilia Blima Schraiber, Marcia Thereza Falcão, André Mota. Humanidades como disciplina na graduação em medicina. Rev Bras Educ Méd, 37, 3 (2013): $455-463$.

Bottega, Clarissa, Luiz Fernandes de Campos. Considerações sobre a Eutanásia, distanásia e ortotanásia e a bioética. Rev. Jurídica Universidade de Cuiabá 13, 2 (2011): 39-62.

Caldin, Clarice Fortkamp. A aplicabilidade terapêutica de textos literários para crianças. Encontros Bibli: Revista Eletrônica de Biblioteconomia e Ciência da Informação, 18 (2004): 72-89. Disponível em: https://periodicos.ufsc.br/index.php/eb/article/view/15182924.2004v9n18p72/5474.

Charon, Rita. Narrative medicine: a model for empathy, reflection, profession, and trust. JAMA 286 (2001):1897-902.

Churchill, Larry. Why literature and medicine? Literature and Medicine, 1, 1 (1982): 35-36.

Cruz, Poliana Oliveira, Thaís Bandeira Carvalho, Luca Di Pace Pinheiro, Patricia Estela Giovannini, Ellany Gurgel Nascimento, Thalles Allyrio Araújo Fernandes. Percepção da efetividade dos métodos de ensino utilizados em um Curso de Medicina do Nordeste do Brasil. Rev Bras Educ Méd, 43, 2 (2019): 40-47.

Finger Schneider, Raquel Elisabete, Sandra Djambolakdijan Torossian. Contos de fadas: de sua origem à clínica contemporânea. Psicol. Rev. 15, 2 (2009): 132-148.

Geovanini, Fátima, Ana Luisa Rocha Mallet, Luciana de Paula Lima Andrade, Renata Silva Monteiro, David. Kestenberg. Todo aluno tem uma história para contar: narrativas dos estudantes na disciplina de humanidades médicas. Revista Eletrônica Estácio Saúde, 5, 2 (2016): 169175.

Lima, Artur Dias, Marcos da Costa Silva, Lídia Cristina Ribeiro, Maria Teresita Bendicho, Hermila Tavares Guedes, Denise Carneiro Lemaire. Avaliação, ensinagem e metodologias ativas: uma experiência vivenciada no componente curricular - Mecanismos de Agressão e de Defesa, no Curso de Medicina da Universidade do Estado da Bahia, Brasil. Rev Bras Educ Méd, 43, 2 (2019): 216-224.

Ribeiro da Silva, Marlon, Dante Marcello Claramonte Gallian, Paulo Schor. Literatura e Humanização: uma experiência didática de educação humanística em saúde. Rev Bras Educ Méd, 40, 1 (2016): 93-101.

Mallet, Ana Luisa Rocha, Fátima Geovanini, Luciana Andrade, David Kestenberg. A diferent heart in children's literature: the juvenile literature in medical education. International Journal of Cardiovascular Sciences, 33, 2 (2020):185-187. 
Mallet, Ana Luisa Rocha, Fátima Geovanini, Luciana Andrade, David Kestenberg. Cardiology and films: an important teaching tool. International Journal of Cardiovascular Sciences 31, 4 (2018): 451-453.

Mendes, Miguel. Documentário José e Pilar - tudo pode ser contado de outra maneira. Direção: Miguel Gonçalves Mendes, Edição: Cláudia Rita Oliveira. 2010. Disponível em: https://www.youtube.com/watch?v=d-V7j-WKHVs

Saramago, Jose. As Intermitências da Morte. 17ª reimpressão. São Paulo, Companhia das Letras, 2016.

Saramago, Jose. Ensaio sobre a Cegueira. 76ª reimpressão. São Paulo, Companhia das Letras, 2017.

World Health Organization. WHO | WHO Director-General's opening remarks at the media briefing on COVID-19 - 11 March 2020. Disponível em: https://www.who.int/director-general/speeches/detail/who-director-general-s-opening-remarks-at-the-media-briefing-on-covid-19--11-march-2020. 